\title{
Contribuciones transmetodológicas para el análisis de procesos comunicativos contemporáneos
}

\author{
Transmethodological contribution for the analyze contemporary processes
}

\author{
Alberto Efendy MALDONADO GÓMEZ DE LA TORRE \\ UNISINOS - Brasil / CIESPAL - Ecuador \\ efendymaldonado@gmail.com
}

Cómo citar este artículo: MALDONADO GÓMEZ DE LA TORRE, Alberto Efendy (2016): «Contribuciones transmetodológicas para el análisis de procesos comunicativos contemporáneos», Mediaciones Sociales, no 15, pp. 1-15. DOI: http://dx.doi.org/10.5209/MESO.54540

Recibido: 26 de octubre de 2016.

Aceptado: 22 de noviembre de 2016.

\begin{abstract}
RESUMEN
El objetivo de este artículo es profundizar la reflexión teórico-metodológica sobre procesos mediáticos, que configuran transformaciones expresivas en los modos y en las formas de construir espacios de encuentro (tecno-cultural comunicativo). La articulación teórica incluye pensadores críticos de varias corrientes epistemológicas (Gortari, Bachelard, Cassirer, Harvey, Mattelart, Norris, Santos, Sartre), que dialogan con el eje transmetodológico (Maldonado) para analizar procesos contemporáneos de constitución de ciudadanías comunicativas y transformaciones socioculturales.
\end{abstract}

PALABRAS CLAVE: ciudadanía comunicativa, reflexiones teórico-metodológicas, sujeto comunicante, transmetodología, transformaciones comunicacionales.

\section{ABSTRACT}

The objective of this paper is to deepen the theoretical and methodological reflection on media processes that shape expressive transformations in modes and ways to build meeting places (in a communicative technocultural sense). The theoretical articulation includes critical thinkers of various epistemological currents (Gortari, Bachelard, Cassirer, Harvey, Mattelart, Norris, Santos, Sar- 
tre), that dialogue with the transmethodological axis (Maldonado) to analyze contemporary processes of forming communicative citizenship and socio-cultural transformations.

KEYWORDS: communicative citizenship, theoretical and methodological reflections, communicating subject, transmethodological, communicational transformations.

Sumario: 1. Introducción. 2. Transformaciones y obstáculos en las condiciones de producción tecno-culturales comunicativas. 3. El desafío tecno-cultural. 4. Diálogos y contribuciones transmetodológicos. 5. Conclusiones. Bibliografía.

\section{INTRODUCCIÓN}

Este artículo trabaja aspectos teórico-metodológicos de carácter comunicativo, que problematiza transformaciones mediáticas en la contemporaneidad. Sitúa las condiciones de producción de comunicación y los obstáculos tecno-culturales, como ejes articuladores de su reflexión. El análisis se fundamenta y se inspira en epistemologías históricas, genéticas, existenciales, dialécticas y realistas, en diálogo con investigaciones sistemáticas realizadas por el autor del texto y los equipos de investigación que coordina. El objetivo teórico propuesto busca desestabilizar posturas teóricas de carácter funcional, instrumental y positivista.

\section{TRANSFORMACIONES Y OBSTÁCULOS EN LAS CONDICIONES DE PRODUCCIÓN TECNO- CULTURALES COMUNICATIVAS}

En la historia del pensamiento latinoamericano, Eli de Gortari (1980) mostró la complejidad, amplitud, sofisticación y fecundidad de los ingenieros, cosmólogos, arquitectos, ecólogos y urbanistas del México indígena, pre-colonial, libre y autónomo de los poderes imperiales europeos. En Brasil, Darcy Ribeiro (2007), Lévi-Strauss (2001) y el conjunto de la investigación crítica, libre de las ataduras neocoloniales de pensamiento, mostraron la riqueza, la calidad, la complejidad y la amplitud de los pensadores indígenas en las selvas de América del Sur. Sus saberes estaban orientados a la dimensión ecológica, micro-sociológica, botánica, sexual, geográfica y espiritual. El hecho es que, en varios puntos de los territorios americanos, existían comunidades humanas organizadas, de acuerdo con una diversidad de cosmovisiones, políticas de gobierno, valores éticos, premisas filosóficas, narrativas históricas y saberes aglutinados en lógicas y principios, que eran el resultado de miles de años de reflexiones, aprendizajes, éxodos, luchas y existencia fecunda. En términos ecológicos, sociológicos, antropológicos y políticos, varias de esas vertientes de pensamiento y 
vida social superaban a las formaciones económico-sociales europeas, que predominaban en la época.

En tiempos de embestida de las ideas patriarcales, neoliberales, neoconservadoras, militaristas, depredadoras, imperiales, xenófobas y racistas, es imprescindible establecer en los preámbulos de nuestras reflexiones una línea epistemológica de continuidad; tanto en el sentido de situar, reconocer y reconstruir nuestras confluencias de conocimiento americano (utilizo el término para enfrentar el secuestro lingüístico de este por los anglosajones), como en el sentido de nutrirnos de las sabidurías producidas en el conjunto del planeta. En esta última perspectiva, necesitamos trabajar, también, epistemologías de ruptura, porque los modelos, paradigmas e institucionalizaciones preponderantes castran la producción ampliada de conocimiento y de arte, monopolizan los recursos de investigación y orientan las inversiones en investigación hacia la maximización de los lucros, en contra de las necesidades del planeta, de las comunidades humanas y de la vida.

No hay posibilidad de formular propuestas científicas realistas, transformadoras y comprometidas con el conjunto de la humanidad (Mattelart, 2014), si no se sitúan las condiciones de producción como referente crucial de argumentación, como nos ha descubierto el pensamiento crítico mundial (Gortari, 1980; Norris, 2006; Sartre, 2011; Harvey, 2014; Hobsbawm, 2011). A mediados de esta segunda década del siglo XXI, problematizar, reflexionar, cuestionar, comprender y construir argumentos que profundicen y amplíen esa categoría, en el campo de las ciencias de la comunicación, es de singular importancia, dadas las profundas transformaciones tecnológicas producidas con la invención de la comunicación digital.

En confrontación con el modelo hegemónico positivista, importantes vertientes críticas desmontan esa concepción instrumental, lineal y mecanicista de pensamiento sobre la comunicación (Winkin, 2000; Mattelart, 2014; Martín Barbero, 2014; Maldonado, 2015). De hecho, la transformación provocada por el conjunto de invenciones realizadas, en el área de software y de hardware en las tres últimas décadas, han provocado desestabilizaciones renovadoras en los procesos de existencia comunicativa (Castells, 2013). Entre estas, una que suscita especial atención es el cambio en la interrelación entre medias y sujetos comunicantes; en esta dinámica, la noción -preponderante y generalizada- de "receptores" ha sido profundamente cuestionada por los nuevos papeles sociales y profesionales de las personas que participan en procesos de comunicación. En efecto, hay un potencial modificador y transformador en la realidad tecnológica, que hace posible la inserción de centenas de millones de personas en prácticas de producción comunicativa de amplia circulación.

Las condiciones de producción de información y comunicación, a partir de la invención tecno-cultural digital, dan continuidad, profundizan y amplían las posibilidades de generar, fabricar, producir y reformular procesos comunicativos diversos. De esta 
manera, las potencialidades de construir medios de comunicación alternativos ${ }^{1}$, populares, subversivos, inventivos y socializantes se fortalecen, reinventan y democratizan. En los inicios del siglo XXI, esta realidad ha hecho posible la proliferación de experiencias comunicativas (Castells, 2013), que han desestructurado los modos de organización (oligopólicos y autoritarios); las lógicas productivas (mecanicistas e instrumentalistas); las premisas de trabajo (neoconservadoras: de fascismo social, y neoliberales: de fundamentalismo de mercado); las interrelaciones productivas (de explotación del trabajo intelectual y manual), y las funciones y finalidades de los medios (mantener el statu quo de altísima concentración de renta, y condicionar la vida simbólica de las poblaciones al reducir sus capacidades comunicativas).

En las dos últimas décadas, un sector significativo de la producción social simbólica, de comunicación e información, ha reconfigurado posibilidades técnicas, estéticas, políticas, sociológicas, antropológicas, sicoanalíticas en una orientación favorable a la estructuración de una ciudadanía comunicativa fecunda (Maldonado, 2015). Es decisivo el proceso de liberación y transparencia de informaciones que brindan los actuales grupos de investigación, observación, producción y socialización. En esa línea, el caso Wikileaks es paradigmático en el contexto internacional (Assange, 2014), y muestra un fenómeno de ruptura con las lógicas criptográficas de concentración de información estratégica (Mattelart, 2009); este colectivo de colectivos, en red, ha colocado a disposición de los ciudadanos comunes del planeta informaciones que hasta el siglo pasado estaban restrictas a grupos de poder, fortalezas de conocimiento y campus universitarios. De manera simultánea, ha permitido que varias teorías de contrapoderes, que presentaban robustez conceptual, tengan a disposición datos empíricos mundiales de relevante expresión. Las asociaciones de hackers, de programadores subversivos y de inventores de dispositivos electrónicos (orientadas hacia el buen vivir) han puesto a disposición recursos tecnológicos que hacen posible el acceso ampliado a recursos de producción comunicativa (Alonso et al., 2012).

La revolución comunicativa que significó la instauración mundial de la lógica del código abierto todavía está en su fase inicial; de hecho, la magnífica amplitud de interrelaciones humanas que esta invención ha concretizado, ha provocado cambios cualitativos substanciales en las fuerzas productivas, tanto en la economía capitalista (Piketty, 2014) cuanto en la economía solidaria. Este mismo proceso, de modo dialéctico, ha generado el fortalecimiento de los sistemas y esquemas panópticos, como muy bien lo ha expuesto Edward Snowden. Desde mediados del siglo XX, las estrategias de vigilancia, control y penetración militar en el mundo han hecho del complejo militar industrial estadounidense el núcleo central de diseño de modos de vida devastadores, de apoyo a tecnologías de destrucción masiva, de realización mundial de la lógica de la guerra (Mattelart, 2009; Chomsky, 2004), en especial, contra los pueblos

\footnotetext{
${ }^{1}$ Medios alternativos a los poderes hegemónicos y a las formas de cultura conservadoras.
} 
de Asia, África y América Latina. Los varios millones de muertos, desaparecidos, heridos y desplazados en el último siglo son muestra fehaciente de eso.

\section{EL DESAFÍO TECNO-CULTURAL}

El aspecto que más dificultades presenta para las nuevas configuraciones comunicativas es el tecno-cultural. Y, en esta dimensión, se constatan expresivas dificultades para lidiar con epistemologías y lógicas de ruptura. Lo común es producir discursos críticos en el nivel de los contenidos, sin reformular la lógica enunciativa y los modos de producir la comunicación. Este conservadorismo es pronunciado en el caso del periodismo; en efecto, en la actualidad, hay procesos de comunicación alternativos importantísimos; que, sin embargo, trabajan lógicas dicotómicas, narrativas de reducida contextualización, adjetivaciones limitadoras de la complejidad de lo real, esquemas discursivos propios de los modelos comerciales predominantes (Faxina, 2012; Strassburger, 2012), y modos de relación con los públicos de carácter vertical, que dificultan una socialización fecunda mayor, y que consideran a los ciudadanos como agentes subalternos en los procesos de producción de sentido, y no como sujetos protagonistas de la comunicación.

Las dificultades para el cambio en el orden cultural mediático, no obstante la riqueza y la potencialidad digital, demuestran la presencia articuladora, mediadora y condicionante de matrices simbólicas seculares; simultáneamente, muestran la fuerza de las lógicas del marketing (mercadeo simbólico) en los campos político y religioso. Así, las campañas, los oficios religiosos, la comunicación mediática de estas áreas siguen lógicas de mercadeo funcional que degradan la calidad argumentativa, ética, educativa y cultural de estos discursos. Y es en esta realidad que los estrategas de las izquierdas restringen (Corcuff, 2015), en mucho, su producción simbólica, y la encuadran en la fabricación de celebridades (candidatos); en la producción de simulacros (los procesos históricos son editados en términos de espectáculos); en la reproducción de matrices culturales problemáticas (por ejemplo, la fabricación simbólica de ortodoxias y de líderes). Los aspectos étnicos, ecológicos, de género, de experimentaciones sociales (nuevos mundos), y epistemológicos son tratados -en la mayor parte de los casos- de manera rápida y con limitada argumentación. En la dimensión estética, los productos comunicativos son construidos de manera reductora, y evitan expresar combinaciones de formas, contenidos y sensibilidades de la multiplicidad humana.

Los obstáculos para la transformación sociocultural tienen una raíz poderosa en la actualización constante de matrices culturales seculares; es el caso del patriarcalismo que produce cultura machista en expansión en la mayoría de contextos mediáticos y sociales. La producción cinematográfica de Hollywood, referente mundial en este sector, destina a las mujeres pocos papeles protagónicos (Pires \& Maldonado, 2015). 
Las investigaciones sobre receptividad comunicativa, que hemos producido y dirigido en las dos últimas décadas (Maldonado, 2014), comprueban el carácter contradictorio, dinámico, mutable e inestable de los públicos de los sistemas mediáticos. Si bien hay personas que establecen contratos de lectura, que duran décadas, también hay individuos que establecen pactos de sentido de corta o mediana duración. El carácter de esas interrelaciones depende del campo social en cuestión; por ejemplo, el campo religioso es más estable; la ficción seriada melodramática también tiene una significativa estabilidad; así, encontramos grandes segmentos sociales que establecen contratos de lectura por décadas; pero, en sentido diferente, el campo político, el campo económico y el campo sicológico (social) son preponderantemente inestables en sus configuraciones semióticas (Maldonado, 2009). Entre el conjunto de aspectos que condicionan esta realidad, destacamos, en términos causales, la lógica de aceleración de los procesos socioeconómicos, dadas las dinámicas del capitalismo hegemónico contemporáneo (Harvey, 2014): aumento constante de la productividad y de la intensidad del trabajo; aumento en la concentración de la renta (Piketty, 2014); invasión de los tiempos de entretenimiento y de descanso; temporalidades sociales estresantes; fragmentación micro y macro social depredadora; interrelaciones tecnoculturales masivas (uso amplio e intenso de los nano-computadores); culturas cotidianas condicionadas de manera intensa y amplia por las lógicas del consumo; sistemas de vigilancia y control orientados a garantizar las estructuras de dominación (Mattelart, 2009).

\section{DIÁLOGOS Y CONTRIBUCIONES TRANSMETODOLÓGICOS}

La transmetodología, como vertiente epistemológica transformadora en el campo de las ciencias de la comunicación, propone la confluencia de estrategias y procedimientos de investigación para la problematización de realidades comunicacionales y mediáticas, de orden multidimensional y complejo. Los procesos históricos de estructuración de los sistemas mediáticos y la constitución de modos, formas y culturas comunicacionales, mediadas por tecnologías electrónicas digitales, condicionan la formulación de problemas de investigación, cambian las exigencias para la construcción de objetos empíricos y teóricos, y demandan confluencias teóricas interdisciplinares e intermetodológicas, que garanticen aproximaciones, inmersiones, reconocimientos, interpretaciones y resoluciones fecundos.

Es necesario construir procedimientos y teorizaciones que den continuidad a las sabidurías seculares, y a los conocimientos científicos, que han contribuido y contribuyen para el bien-vivir de la humanidad; simultáneamente, es imprescindible diseñar proyectos y formular teorías de ruptura, que asuman el desafío dialéctico de generar una investigación adecuada a una realidad de configuraciones hipertextuales y de procesos transmediáticos. 
En la actual coyuntura histórica de vigencia de sistemas de control, espionaje y represión de las manifestaciones y culturas de transformación, es decisivo contribuir al fortalecimiento del concepto de sujetos históricos comunicantes, como alternativa fértil a las nociones reductoras de receptor, destinatario, usuario y otras que disminuyen y fragmentan el carácter múltiple y diverso de los seres humanos en su dimensión comunicativa. Cabe explicitar, para los simpatizantes de los juegos etimológicos, que en esta argumentación no se trabaja con la acepción reductora de subjetu como adjetivo de origen latino, que hace referencia a súbdito, a cautivo, a adscrito, a sometido, a dependiente. La opción dialéctico-filosófica que se trabaja es la de sujeto como individuo real; capaz de realizar acciones, pensar, optar, determinar, tener y producir derechos, establecer relaciones, construir historia, fabricar cultura, inventar y producir conocimiento.

El sujeto comunicante que pensamos es multidimensional; por una parte, existe y produce en una dimensión intercultural con sus diversidades, riquezas, conflictos, flujos, choques, aprendizajes y configuraciones, que lo tornan un ser en movimiento, en inestabilidad, en continuas interrelaciones tecno-simbólicas. Por otra, es un sujeto político que tiene un conjunto de opiniones, percepciones, valoraciones, posiciones, ideologías y esquemas de comportamiento, de apreciación y de acción, que lo definen como parte de una expresión política, o de una corriente política (conservadora, liberal, socialista, anarquista, fascista, comunista, etc.), de la cual no será necesariamente un militante; pero para la cual actuará en los más diversos escenarios (bar, iglesia, club, barrio, plaza, institución, etc.). El sujeto comunicante es también un sujeto social concreto; miembro de determinada clase, fracción, estamento, sector. En esa dimensión (macro, micro, meso social), produce un conjunto de interacciones, de lazos, de pactos, de alianzas, de confrontaciones; como también de configuraciones colectivas, comunitarias, institucionales, grupales, familiares, territoriales, que producen la sociedad en su cotidianidad, a partir de las condiciones estructurales, sistémicas e institucionales en las cuales se ubica. En esta dimensión social, ocupa lugar central la actividad productiva, el trabajo humano en su capacidad de fabricar mundo; actividad que actúa como una mediación central en las posiciones y acciones comunicativas.

La crítica de la noción reductora de "receptor", "destinatario" o "usuario", requiere, también, la inclusión de los aspectos culturales que configuran la dimensión simbólica aglutinante de los procesos de producción de significaciones, tanto de los sentidos cosmológicos más generales como de los sentidos comunes más simples y cotidianos. El sujeto comunicante cultural pertenece a determinada cultura (plural), construye sus identidades y su pertinencia en un ethos concreto, en el cual realiza sus intercambios simbólicos, establece un modo de vida sexual, adquiere competencias económicas específicas, y aprende a situarse en una trama de poderes (campos de fuerzas en tensión) para existir. 
El sujeto comunicante que concebimos es histórico; por lo tanto, está condicionado por determinadas estructuras, sistemas, formaciones sociales y modos de producción. Existe en un mundo que no fue definido por él; pero tiene el potencial de construir nuevas historias, procesos de ruptura, de cambio, de renovación y de transformación. Esta potencialidad tiene una imbricación decisiva con la dimensión comunicacional; es en esta que confluyen los múltiples componentes culturales y naturales para generar sujetos que comunican, que están en acción comunicativa, que establecen modos de vida interrelacionales, simbólicos y concretos, para fluir en sus existencias. Estos seres históricos en sus realidades están muy lejos de las especulaciones y de las reducciones teóricas (receptores, destinatarios, usuarios) que los expulsan del mundo en su estructuración concreta.

Los sujetos comunicantes en su existencia histórica son parte de formaciones sociales y de sociedades, en las cuales ejercen papeles y funciones determinadas; están situados en determinados lugares y posiciones; actúan de acuerdo con esquemas, modelos, matrices y parámetros en los cuales fueron formados. Al mismo tiempo, participan de rupturas, cambios y renovaciones cuando las tramas de contradicciones sociales y sus condiciones subjetivas confluyen para explosiones semióticas, filosóficas, políticas y sociales. Estos sujetos se constituyen así en ciudadanos comunicantes; expresan su pertinencia a determinada sociedad, fabrican identidades en interrelación con las distinciones, diferencias y similitudes micro y macro sociales. La clase, la fracción, el estamento los marcan; pero, al mismo tiempo, los potencializan para transformaciones. Los éxodos los confrontan a los desafíos de las necesidades interculturales, de los aprendizajes múltiples, de la diversidad creativa, como condición necesaria para un bien-vivir.

Los sujetos comunicantes son los protagonistas de la ciudadanía comunicativa, que va mucho más allá de lo jurídico y de lo político formal, que comprende el ejercicio del poder y de la participación histórica en términos multidimensionales. Es así que las sociedades se estructuran, se reconstruyen y se destruyen con la participación decisiva de los procesos comunicacionales; en estos, los sujetos históricos colectivos (clase, fracción, etnia, partido, vertiente, etc.) y los sujetos individuales intervienen y producen determinados resultados (estructuraciones, dispositivos, configuraciones, culturas, técnicas, estrategias, etc.). Cabe decir, en ese sentido, que la hegemonía es producida en las interrelaciones; que sin la complicidad de los subalternos no hay poder dominante, no hay poder transnacional imperial.

La ciudadanía comunicativa demanda una acción inventiva en busca del cambio de condiciones de circulación, apreciación, producción y realización de la comunicación; en América Latina es generalizada la forma caudillista, concentradora, monopólica y hasta oligopólica de ejercicio del poder mediático. Esta realidad anacrónica condiciona todos los campos sociales, atraviesa el mundo político y posiciona al príncipe elec- 
trónico (sistemas mediáticos hegemónicos) como principal protagonista y articulador del quehacer político. Este sujeto político hegemónico es constituido por unas pocas familias oligárquicas (Marinho, Azcárraga, Cisneros, Abrabanel, Saad, Slim, Macedo, Sirosky, Noble, Edwards Eastman, etc.), que controlan la circulación de informaciones, mensajes y discursos, sin responsabilidad social; actúan cotidianamente para preservar intereses hegemónicos que afectan la vida socioeconómica de la mayoría de la población; definen estrategias de excepción, que debilitan fuertemente los estados de derecho y las recientes democracias latinoamericanas. El caso paradigmático es el golpe de Estado diseñado y realizado en Brasil entre 2015 y 2016 (Pimenta, 2016; Proner et al., 2016; Rovai et al., 2016; Santos et al., 2016; Souza, 2016); este sintetiza la acción depredadora de los sectores oligárquicos y neofascistas latinoamericanos para debilitar las democracias en la región. El estado de excepción está en funcionamiento, gracias a la articulación de sectores neoconservadores del poder judiciario, de partidos de derecha, de leyendas políticas de alquiler, de sectores neopentecostales politizados y de fracciones neofascistas, que predican ideologías retardatarias xenofóbicas, racistas, misóginas, homofóbicas y neofascistas; en sintonía con el complejo informático, militar, industrial, en especial la NSA (participación confirmada por los documentos revelados por Edward Snowden).

En la actual coyuntura brasileña y latinoamericana, la construcción de una ciudadanía comunicativa (democrática, auténtica, transclasista, multiétnica, multicultural, multinacional y transformadora) es un desafío central para la existencia de una vida digna.

La acción retórica eficiente de persuasión, de los grandes sistemas mediáticos hegemónicos, para controlar las "mentes y los corazones" de un número expresivo de la población en la región, es un hecho en el cual el príncipe electrónico muestra fuerza política decisiva. En la fase histórica actual, su capacidad de penetración en todas las clases sociales y su poder de condicionar los modos de vida comunicativos de centenas de millones de personas en el continente se mantiene, y define los renovados encuadramientos autoritarios de orden jurídico y político. Es una novedad en América Latina la actual competencia, alcanzada por las oligarquías, para establecer regímenes de excepción y dar golpes de Estado sin necesidad de la intervención represiva, directa, militar. Hoy constatamos cómo sectores del sistema jurídico, partidos oligárquicos y fuerzas represivas confluyen en líneas estratégicas coherentes con los lineamentos del poder hegemónico transnacional.

No es plausible, en términos de la problemática de la formación de investigadores y profesionales de la comunicación, seguir conciliando con las ilusiones neocoloniales que el funcionalismo y el positivismo anglosajones promueven en nuestros campos académicos de comunicación. Es imprescindible diseñar líneas de investigación, asignaturas, seminarios, cursos, talleres, coloquios, encuentros, programas y estrategias 
que ubiquen el concepto de ciudadanía comunicativa en un lugar importante de los quehaceres de producción de conocimiento y de educación. Una ciudadanía multidimensional, que combine su dimensión científica con su dimensión política, su dimensión comunicativa con su dimensión educativa, su dimensión jurídica con su dimensión existencial cotidiana, su dimensión intercultural con su dimensión micro social, su dimensión cosmopolita con su dimensión local, su dimensión lúdica con su dimensión productiva, su dimensión afectiva con su dimensión fecunda, su dimensión simbólica con su dimensión inventiva, su dimensión industrial con su dimensión ecológica. Y, simultáneamente, articule todas las relaciones inventivas entre estas.

Sin democratización de la comunicación, el orden oligárquico continuará vigente por largo tiempo. Los "latifundios" mediáticos continúan controlando los posicionamientos políticos de un expresivo sector de la población, gracias a su acción estratégica continua de distorsión de la realidad, de las problemáticas y de las necesidades. Es un desafío urgente para los grupos de investigación, los núcleos de trabajo, los movimientos socio-comunicacionales, los intelectuales críticos y todos los sectores democráticos definir líneas de articulación estratégica y planes de trabajo concretos para debilitar el poder mediático oligárquico.

En el campo del trabajo de investigación y producción de conocimiento, que es el que nos ocupa, es importante continuar, profundizar, ampliar y perfeccionar nuestras metodologías críticas transformadoras, mediante una praxis teórica rigurosa, flexible, sistemática, abierta, dialéctica e inventiva de conocimiento del mundo. Tenemos que nutrirnos de las sabidurías y conocimientos producidos por el conjunto de la humanidad, y, a la vez, confrontar el logocentrismo y el etnocentrismo anglosajón, y todas las formas de intelectualismo, de especulación teórica y de trabajo abstracto elitista, segregacionista, exclusivista y autoritario.

Las pretensiones exclusivistas de comprensión del mundo, entre las cuales se destacan el positivismo y el pragmatismo anglosajones, tienen que ser desmontadas mediante un trabajo de producción de argumentos, conceptos, teorías, proyectos y propuestas renovadores y transformadores; la investigación teórica debe ser fomentada en todos los proyectos, desde los básicos en nivel de iniciación científica hasta los avanzados en el pos doctorado. Los proyectos operativos y empíricos deben incluir en sus diseños la presencia de "teorías en acto" (técnicas) que sean coherentes con las estrategias de ruptura del conservadorismo académico, intelectual e investigativo. El desafío teórico transformador no permite dejar para el conservadorismo el quehacer teórico diario en las facultades, escuelas, cursos, programas y proyectos; es necesario intensificar y ampliar la crítica; es imprescindible producir alternativas teóricas consistentes, realistas, fuertes, sofisticadas y renovadoras sobre los problemas/objeto concretos de investigación y sobre las concepciones necesarias para producir otros mundos posibles. 
En la dimensión empírica de las investigaciones, la ruptura con la hegemonía conservadora, neocolonial y autoritaria exige un esfuerzo central de praxis de ciudadanía cientifica; es necesario, desde la fase previa a la formulación de los proyectos, atravesar los pensamientos, los diseños, las propuestas, los mapas mentales y las experimentaciones metodológicas con necesidades históricas, económicas, políticas y culturales de transformación. La justificación de la investigación no puede quedar reducida a intereses coyunturales, o a oportunismos institucionales y personales; los problemas deben ser relevantes para la especie y para la vida. Los objetos/problema de investigación (propuestos) solicitan objetos inmediatos de referencia relevante, que permitan cuestionamientos de fondo de la realidad existente, y ofrezcan condiciones favorables a la comprensión de la integralidad de los procesos y fenómenos. Lo empírico existente y lo empírico construido piden tratamientos desestabilizadores de los rituales repetitivos de la "ciencia oficial"; al mismo tiempo, exigen la reconstrucción del mundo de la vida, la reformulación de las formaciones sociales, y la proposición de alternativas socio-culturales de existencia para la instauración de modos, formas y prácticas de investigación empírica comprometidas, y constructoras de transformación.

En América Latina es importante investigar los procesos comunicacionales emancipadores, revolucionarios, alternativos, subalternos y renovadores de las clases, los grupos, las etnias, los movimientos, las tribus, las comunidades y las organizaciones que durante los dos últimos siglos han generado culturas de solidaridad, crítica, y de problematización de la modernidad. Es necesario ampliar y profundizar la investigación sobre los procesos de constitución de los sistemas y redes mediáticos oligárquicos; hay valiosos trabajos al respecto, pero necesitan de grandes confluencias argumentativas para que el príncipe electrónico sea develado en su complejidad, eficiencia y perversidad.

La multiplicidad cultural latinoamericana presenta una riqueza simbólica, espiritual, afectiva, psicológica, cosmológica y ecológica expresiva, tanto en su intensidad (y fuerza) cuanto en su ampliación. Este potencial requiere de un trabajo de reflexión epistemológica, y de formulación de proyectos de investigación, que busquen comprender y establecer nexos entre la dimensión científica, la dimensión educativa, la dimensión política y esa fuente crucial de poder cultural, que las bifurcaciones y estructuraciones de la región han producido en varios siglos.

\section{CONCLUSIONES}

El desafío epistemológico en el campo de las ciencias de la comunicación demanda un esfuerzo expresivo, orientado a asumir la complejidad tecno-cultural comunicativa que está estructurada en términos de contextos múltiples y ambientes multidimensionales. La combinación constante, en los usos y apropiaciones mediáticas, de lo digital con lo presencial, hace de los procesos comunicativos contemporáneos un 
conjunto problemático que solicita estrategias transmetodológicas. En primer lugar, porque cada objeto de referencia demanda aproximaciones, lógicas, procedimientos y reconstrucciones distintos. En segundo término, porque ninguna técnica, procedimiento o método particular es suficiente para abordar la multiplicidad compleja y diversa de los procesos comunicacionales y mediáticos actuales. Finalmente, porque los conjuntos de conceptos y argumentos (teorías), que se interrelacionan con las problemáticas empíricas, exigen problematizaciones teóricas transdisciplinares (cada conjunto de teorías ofrece posibilidades distintas y propone direcciones diversas; hay varias teorías pertinentes y fecundas para la problemática trabajada). Hoy la complejidad de lo digital/analógico requiere de combinaciones, mezclas, reconstrucciones, reformulaciones y propuestas que constituyan interpretaciones transdisciplinares.

Producir y construir espacios comunicacionales de encuentro comunicativo en la contemporaneidad requiere de investigaciones multifocales, multidimensionales y multicontextuales, que trabajen la riqueza cultural latinoamericana, en sus diversidades subversivas del modo de vida capitalista, y problematicen los múltiplos aspectos, componentes, dispositivos, sistemas, modos, formas, estrategias, tácticas, narrativas, estructuras, expresiones, manifestaciones, discursos, etc. de las actuales formaciones comunicacionales en su complejidad y dinamismo.

Nuestra opción epistemológica es por la confluencia y la confrontación de estrategias metodológicas, a partir de un eje de dialécticas múltiples que confronte las fuerzas en conflicto, los vínculos internos, los nexos externos, las lógicas, las concepciones, los argumentos, las descripciones y las interpretaciones de los procesos. Esta transmetodología, exigida por la contemporaneidad, reclama la producción de condiciones de investigación, y producción teórica, que rompan con el marasmo burocrático conservador, predominante en las instituciones académicas. Para esto, es necesario reconstruir lo mejor del conocimiento epistemológico y metodológico que nos brinda la experiencia humana en los últimos milenios; tenemos que problematizar la contemporaneidad sin esconder y borrar las revoluciones científicas, de sabidurías y de conocimientos generadas por la especie; hay que enfrentar las modas "telegráficas y superficiales" con densidad y trascendencia argumentativas, con investigación histórica seria, dinámica, crítica y flexible. Una epistemología histórica de la comunicación, trabajada en el conjunto de los proyectos y de las argumentaciones, articulará importantes aspectos críticos renovadores y constructores de conocimiento.

Enfatizamos la necesidad de producir problematizaciones metodológicas necesarias, y pertinentes, en todo proceso y proyecto de investigación. En la actualidad, la mayoría de las disertaciones, tesis, trabajos de conclusión, monografías y artículos, del área de comunicación, reducen este trabajo a la adopción, aplicación y reproducción de procedimientos, y de presupuestos y de modelos metodológicos que han alcanzado amplio reconocimiento; o, peor, que están de moda; o, también, que los 
poderes institucionales indican como opción confortable para la aprobación de proyectos académicos. El desafío metodológico para producir conocimiento es otro: implica una construcción metodológica pertinente al problema/objeto concreto en sus dimensiones técnica, metódica, teórica y epistemológica; para esto, el proyecto se nutre de la riqueza estratégica de conocimiento producido por la humanidad; pero, necesariamente, reconstruye, articula, se desplaza, descubre, monta, propone, establece nexos, critica, reformula; contribuye a la producción de conocimiento en su existencia histórica concreta, en su compromiso social y político con las necesidades de la vida. Precisamos asumir este desafío en beneficio de la investigación, del conocimiento y del buen vivir.

\section{BIBLIOGRAFÍA}

ALONSO, M. C. et al. (2012): Ciberespacio y resistencias: exploración en la cultura digital. Buenos Aires: Hekht.

ASSANGE, J. (2014): Cuando Google encontró a Wikileaks. Buenos Aires: Capital Intelectual.

BACHELARD, G. (1983): Epistemologia. Rio de Janeiro: Zahar.

CASSIRER, E. (1993): El problema del conocimiento. Vol. 1. México D. F.: Fondo de Cultura Económica.

CASTELLS, M. (2013): Redes de indignação e esperança: Movimentos sociais na era da internet. Rio de Janeiro.: Zahar.

CORCUFF, P. (2015): “¿Qué ha pasado con la teoría crítica? Problemas, intereses en juego y pistas", Cultura y Representaciones Sociales, vol. 9, no 18, pp. 63-79.

FAXINA, E. (2012): Do mercado à cidadania: o desafio das transformações dos sujeitos discursivos, das institucionalidades e das narrativas jornalísticas na TV pública brasileira. Porto Alegre: PPGCC-UNISINOS. Tesis de doctorado.

CHOMSKY, N. (2004): O império americano: hegemonia ou sobrevivência. Rio de Janeiro: Elsevier.

GORTARI, E. (1980): La ciencia en la historia de México. México: Grijalbo.

HARVEY, D. (2014): Guía de El Capital de Marx (Libro primero). Madrid: Akal.

HOBSBAWM, E. (2011): Como mudar o mundo: Marx e o marxismo, 1840-2011. São Paulo: Companhia das Letras.

LÉVI-STRAUSS, C. (2001): Tristes trópicos. São Paulo: Companhia das Letras.

MALDONADO, A. E. (2009): Transmetodología de la investigación teórica en comunicación: análisis de la vertiente Verón en América Latina. Quito: CIESPAL. 
MALDONADO, A. E. (2014): "Perspectivas transmetodológicas na pesquisa de sujeitos comunicantes em processos de receptividade comunicativa", en Maldonado, A. E. (org.): Panorâmica da investigação em comunicação no Brasil: processos receptivos, cidadania e dimensão digital. Salamanca: Comunicación Social, pp. 17-40.

MALDONADO, A. E. (2015): Epistemología de la comunicación: análisis de la vertiente Mattelart en América Latina. Quito: CIESPAL.

MARTín-BARBERO, J. (2014): A comunicação na educação. São Paulo: Contexto.

MATTELART, A. (2009): Un mundo vigilado. Barcelona: Paidós.

MATTELART, A. (2014): Por una mirada-mundo: conversaciones con Michel Sénécal. Barcelona: Gedisa.

NORRIS, C. (2006): Epistemologia, conceitos-chave em filosofia. Porto Alegre: Artmed.

PIKETTY, T. (2014): El capital en el siglo XXI. Madrid: Fondo de Cultura Económica.

PIMENTA, P. (2016): Democracia, direitos humanos e mídia. São Paulo: Leya.

PIRES, J. e MALDONADO, A. E. (2015): “Globalização, gênero e cidadania no entorno de Jogos Vorazes: disposições culturais e políticas no Brasil e no Vietnã", Revista de Estudos da Comunicação, vol. 16, no 41, pp. 327-344.

PRONER, C. et al. (2016): A resistência ao golpe de 2016. Bauru-São Paulo: Canal 6.

RIBEIRO, D. (2007): As Américas e a civilização. São Paulo: Companhia das Letras.

ROVAI, R. et al. (2016): Golpe 16. Belo Horizonte: Fórum.

SANTOS, B. S. (2006): Gramática do tempo: para uma nova cultura política [Para um novo senso comum. A ciência, o direito e a política na transição paradigmática. Volume IV]. Porto: Afrontamento.

SANTOS, B. S. et al. (2016): Por que gritamos golpe? Para entender o impeachment e a crise política no Brasil. São Paulo: Boitempo.

SARTRE, J. P. (2011): Crítica de la razón dialéctica. I: Teoría de los conjuntos prácticos. Buenos Aires: Losada.

SOUZA, J. (2016): A radiografia do golpe. São Paulo: Leya.

STRASSBURGER, T. (2012): América Latina e cidadania comunicativa: as inter-relações entre sujeitos comunicantes e o portal TELESUR. Porto Alegre: PPGCC-UNISINOS. Tesis de maestría.

WINKIN, Y. (2000): La nouvelle communication. Paris: Éditions du Seuil. 


\begin{abstract}
Alberto Efendy MALdonAdo Gómez de LA TORRE es científico en el área de Ciencias SocialesComunicación. Profesor-Catedrático del Programa de Posgrado en Ciencias de la Comunicación UNISINOS (doctorado y maestría, 1999-2016. Nota CAPES 6: Excelencia académica e científica). Investigador/Consultor/Coordinador de proyectos (CAPES - CNPq - MECD - CIESPAL - SENESCYT - FAPERGS). Investigador Prometeo, Nivel 1-SENESCYT-CIESPAL (2014-2015). Director-Titular de la Cátedra Armand Mattelart-CIESPAL (2016- ). Miembro titular del Colegio de BrasilianistasINTERCOM (2015- ). Director de tesis de doctorado (PhD). Pos-doctorado en Comunicación, Universidad Autónoma de Barcelona (2004-2005). Doctor (PhD) en Ciencias de la Comunicación, Universidad de São Paulo (1999). Premio Honra al Mérito en Investigación de la Cátedra UNESCOUMESP-São Paulo, Brasil, por el conjunto de su obra sobre América Latina. Premio CAPES Director de Tesis (Ministerio de Educación de Brasil) - Ciencias Sociales Aplicadas (2011). Correo electrónico: efendymaldonado@gmail.com.
\end{abstract}

